\title{
Research at the Dr Sheelagh Campbell Laboratory at Teledyne-Impulse-PDM
}

\section{J. Joseph ${ }^{1}$ and J.R. Smith ${ }^{2, *}$}

1Teledyne-Impulse-PDM Ltd, Alton GU34 2YU, UK.

${ }^{2}$ School of Pharmacy and Biomedical Sciences, University of Portsmouth, Portsmouth PO1 2DT, UK

*Corresponding author: james.smith@port.ac.uk

Dr Sheelagh Campbell FIMF, Honorary Editor-in-Chief of Transactions (20022010) and Principal Lecturer at the University of Portsmouth, made important and varied contributions in the fields of chemistry and applied electrochemistry, in research, teaching and committee work, throughout her career. ${ }^{1}$

Following the sad loss of Dr Campbell in 2010, readers and contributors to the journal will be delighted to hear about a research laboratory opened in her name at Teledyne- Impulse-PDM.

Teledyne Impulse-PDM Ltd, a division of the Teledyne Technologies conglomerate, based in Alton, Hampshire, UK, approached one of the authors (JRS), a colleague of Dr Campbell at the University of Portsmouth, to continue the relationship fostered between the company and herself. This relationship centred on a Knowledge Transfer Partnership (KTP) award, with industrial funds from the company, to gain insights into the performance of their underwater cable connector assemblies. These are used for numerous applications, such as transducers, seismic streamers, underwater cameras, light sources, sensors and intercontinental information transfer. They are used on offshore oil rigs, surface vessels, automated and remotely operated vehicles, seismic vessels, subsea pipelines and diving suits. These connectors can be affected by cathodic reactions where high local $\mathrm{pH}$ between the polyurethane (PU) coating and underlying stainless steel causes a reduction in adhesion. ${ }^{2}$ The research enabled Zakari Makama to gain a PhD from Portsmouth in 2011 (he now works at the University of Oklahoma, USA). ${ }^{3}$ Aspects of the research were published in Transactions in 2011,4 for which the authors were awarded the Canning Bicentenary Medal for best practical paper in Transactions in 2012. This research led to a greater understanding and various improvements in the assemblies produced by Teledyne-Impulse-PDM.

The relationship now continues in the form of another $\mathrm{PhD}$ studentship, this time funded entirely by the company. One of the authors (Jamila Joseph, JJ) works 
part-time on her thesis research whilst working full-time at the company. This is an attractive arrangement as the company can access the University's facilities; the company pays a modest tuition fee and a bench fee (for consumables, which is minimal since most of the work is carried out in the workplace); the company graduate is trained in higher research skills, focusing on a real industrial project; and the University gains industrial funding, making use of their expertise and facilities to mutually solve real industrial questions: everyone's a winner, to coin a phrase.

Jamila Joseph's research focuses on characterising and optimising innovative PU systems that do not use mercury compounds as catalysts as a protective coating. Mercury-free PU alternatives (tin, amines, and others), as required under the EC $\mathrm{REACH}$ directive,${ }^{5}$ are being investigated, with material optimisation and accelerated exposure testing being the main thrust of the research work. This takes place predominantly at Teledyne-Impulse-PDM, Alton, in a laboratory named the $\mathrm{Dr}$ Sheelagh Campbell Laboratory, with other testing being carried out at the University of Portsmouth School of Pharmacy and Biomedical Sciences and at the University's Institute of Marine Sciences for real-time exposure tests. The part-time PhD programme is entering its third year and should reach completion next year.

If readers would like more information on how the University could work with your company, in a very cost-effective manner as described here, please contact JRS who would be pleased to hear from you. ${ }^{6}$

If readers would like more information on the capabilities of Teledyne-MarineUK or the supporting capabilities of the Dr Sheelagh Campbell Laboratory, please contact JJ or ALT_PDMsales@Teledyne.com

\section{References}

1. J.P.G. Farr: Trans. IMF, 2010, 88, (5), 225.

2. Z. Makama, I. Doble, D. Nicolson, M.E. Webb and J.R. Smith: J. Adhes. Sci. Technol., 2017, 31, (4), 430-449. doi:10.1080/01694243.2016.1217763

3. Z. Makama: 'Cathodic delamination of modelled sea cable connector assemblies', PhD thesis, University of Portsmouth, 2011.

4. Z. Makama, I. Doble, D. Nicolson, M.E. Webb, I.B. Beech, S.A. Campbell and J.R. Smith: Trans. IMF, 2011, 89, (5), 237-243.

doi:10.1179/174591911X113125496893308

5. Commission Regulation (EU) No 848/2012, 19 September 2012, Amending Annex XVII to Regulation (EC) No 1907/2006 of the European Parliament and of the Council on the Registration, Evaluation, Authorisation and Restriction of Chemicals $(\mathrm{REACH})$ as regards phenylmercury compounds, The European Commission.

6. http://www.jamesrsmith.net/positions.htm 
Transactions of the Institute of Materials Finishing, 95(5) (2017) 239-240.

doi: 10.1080/00202967.2017.1349239

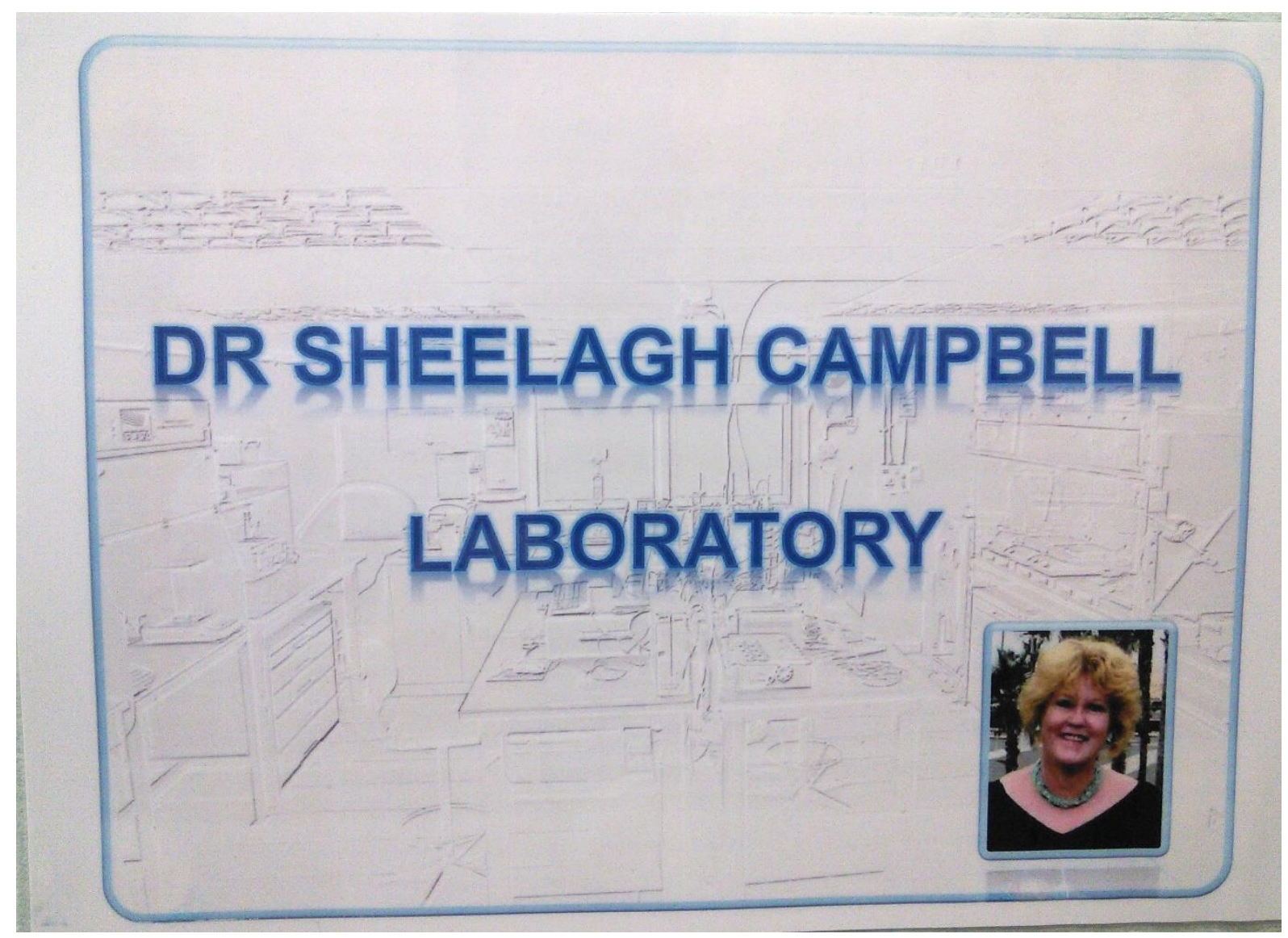

The Dr Sheelagh Campbell Laboratory, at Teledyne-Impulse-PDM, Alton, Hampshire. 
Transactions of the Institute of Materials Finishing, 95(5) (2017) 239-240.

doi: 10.1080/00202967.2017.1349239

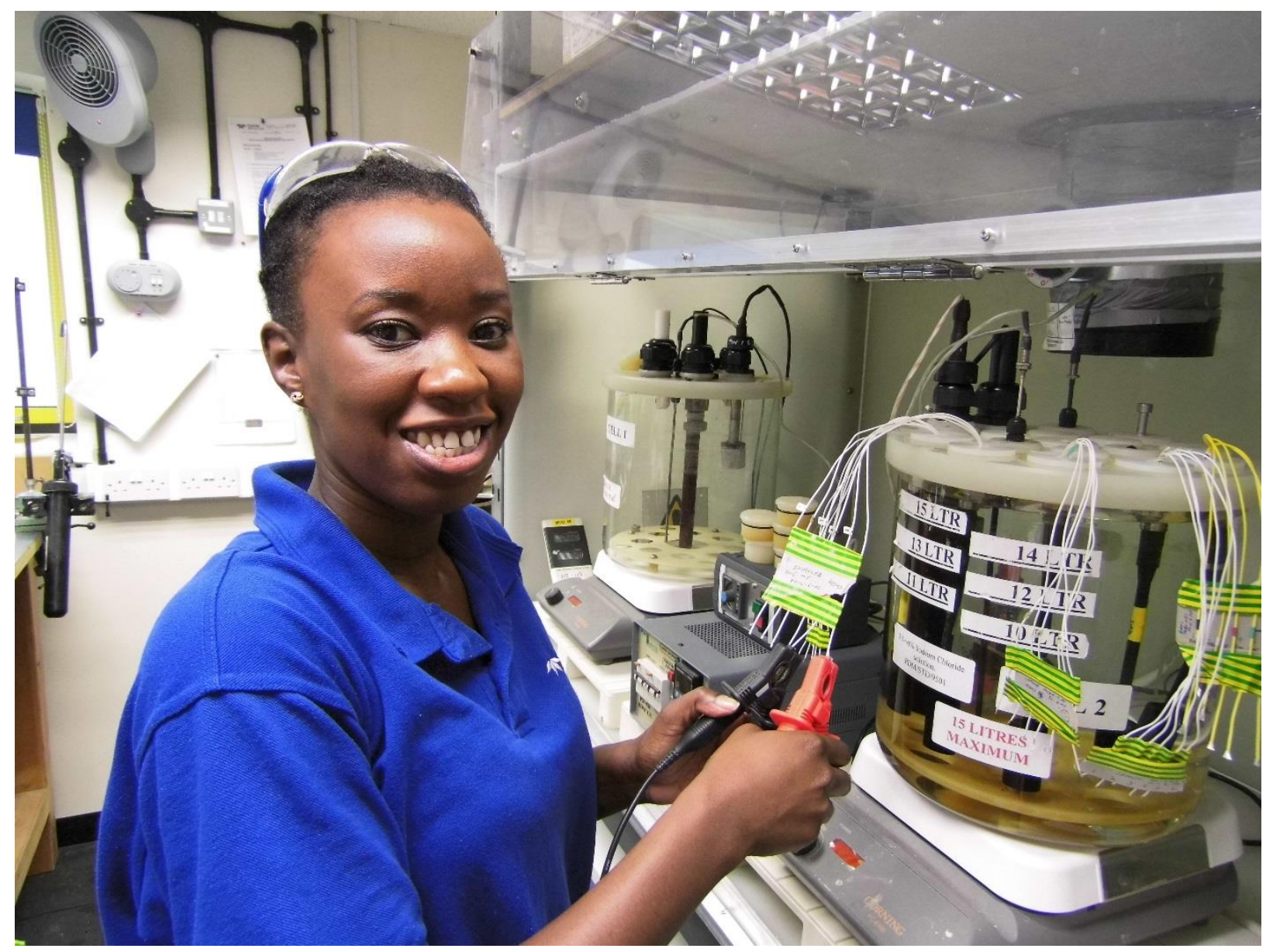

Jamila Joseph carrying out electrochemical measurements on a test cell in the Dr Sheelagh Campbell Laboratory. 


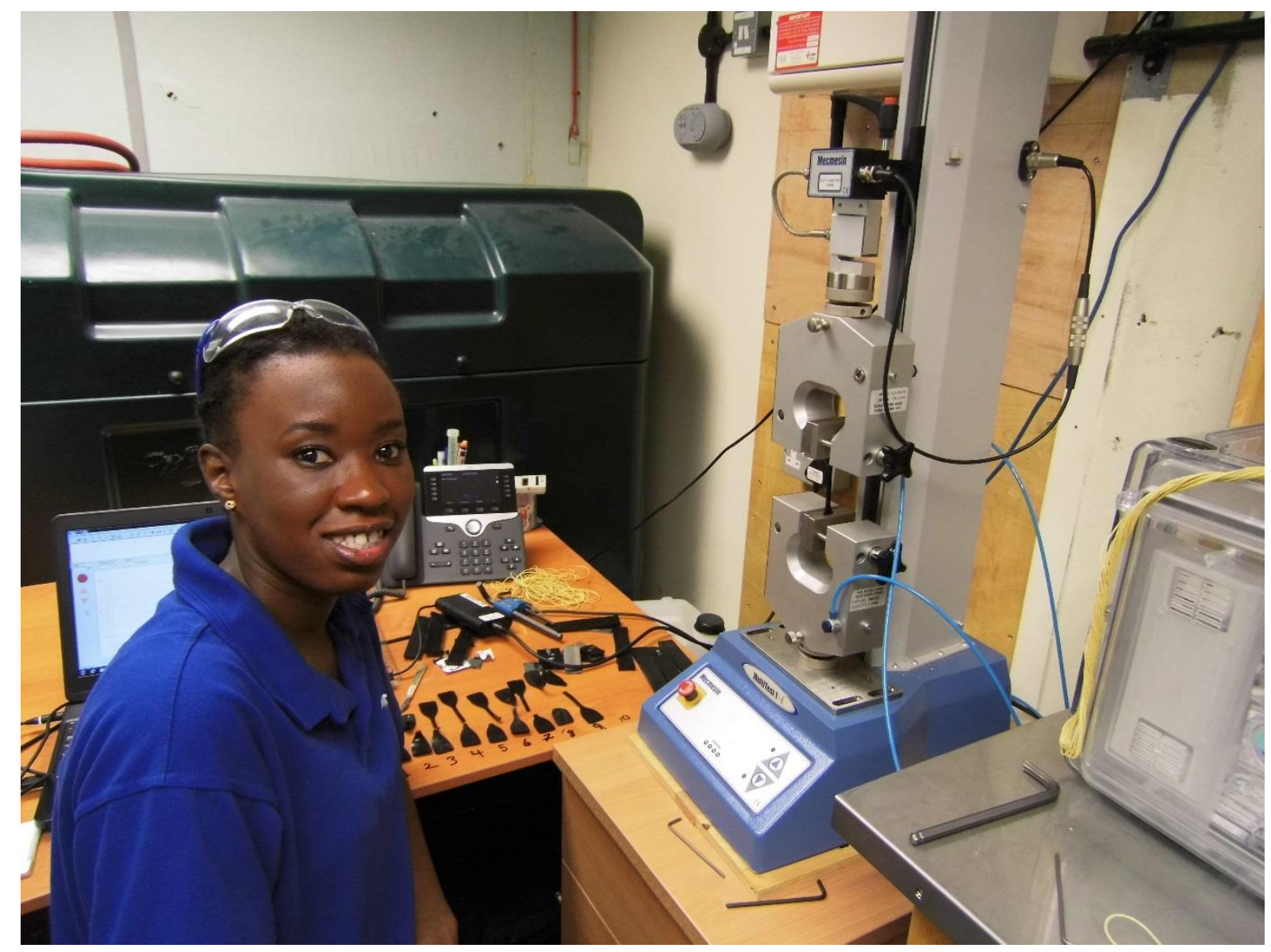

Jamila Joseph, in the Dr Sheelagh Campbell Laboratory, carrying out tensile strength measurements of PU test pieces. The same equipment is used, with minor modification, for measuring PU-metal adhesion bond strengths (pulltests). 